\title{
Making sense of health information technology implementation: A qualitative study protocol
}

\author{
Rebecca R Kitzmiller ${ }^{1 *}$, Ruth A Anderson ${ }^{1}$, Reuben R McDaniel $\mathrm{Jr}^{2}$
}

\begin{abstract}
Background: Implementing new practices, such as health information technology (HIT), is often difficult due to the disruption of the highly coordinated, interdependent processes (e.g., information exchange, communication, relationships) of providing care in hospitals. Thus, HIT implementation may occur slowly as staff members observe and make sense of unexpected disruptions in care. As a critical organizational function, sensemaking, defined as the social process of searching for answers and meaning which drive action, leads to unified understanding, learning, and effective problem solving - strategies that studies have linked to successful change. Project teamwork is a change strategy increasingly used by hospitals that facilitates sensemaking by providing a formal mechanism for team members to share ideas, construct the meaning of events, and take next actions.

Methods: In this longitudinal case study, we aim to examine project teams' sensemaking and action as the team prepares to implement new information technology in a tiertiary care hospital. Based on management and healthcare literature on HIT implementation and project teamwork, we chose sensemaking as an alternative to traditional models for understanding organizational change and teamwork. Our methods choices are derived from this conceptual framework. Data on project team interactions will be prospectively collected through direct observation and organizational document review. Through qualitative methods, we will identify sensemaking patterns and explore variation in sensemaking across teams. Participant demographics will be used to explore variation in sensemaking patterns.

Discussion: Outcomes of this research will be new knowledge about sensemaking patterns of project teams, such as: the antecedents and consequences of the ongoing, evolutionary, social process of implementing HIT; the internal and external factors that influence the project team, including team composition, team member interaction, and interaction between the project team and the larger organization; the ways in which internal and external factors influence project team processes; and the ways in which project team processes facilitate team task accomplishment. These findings will lead to new methods of implementing HIT in hospitals.
\end{abstract}

\section{Background}

Hospital-based health information technology (HIT) implementation research is needed to identify reproducible strategies to eliminate barriers to HIT use and promote its adoption and integration [1]. We found few studies of HIT implementation, and this absence may contribute to the slow and inconsistent adoption of HIT observed in hospitals [2]. This study will address two weaknesses identified in the literature on hospital-based HIT implementation: the absence of evidence about

\footnotetext{
* Correspondence: rebecca.kitzmiller@duke.edu

'School of Nursing, Duke University, 307 Trent Drive, Durham, NC 27502, USA

Full list of author information is available at the end of the article
}

strategies to improve implementation and how to construct and manage project teams tasked with HIT implementation.

In this study, we will prospectively examine a multidisciplinary project team as it prepares to implement a HIT system in a tertiary care hospital. Due to a lack of literature on project teamwork specific to HIT implementation, we rely on the general literature about hospital-based project teamwork. We will use sensemaking to explain the social processes embedded in large scale organization change [3-5], and qualitative methods to achieve the following aims: describe and compare sensemaking across multidisciplinary project teams whose members differ in terms of hierarchical role and 
discipline; describe how the sensemaking of multidisciplinary project teams changes over time; describe how multidisciplinary project teams' sensemaking influences the actions taken; and identify team member behaviors that facilitate or inhibit sensemaking of a multidisciplinary project team.

HIT implementation literature falls into three categories: anecdotal case reports, effectiveness research, and research describing HIT impact in clinical settings. First, the majority of hospital HIT implementation literature is anecdotal and lacks systematic evidence for sound implementation interventions [6,7]. Second, HIT efficacy studies often discuss lessons learned; however these lessons were explanations of findings, rather than empirical observations $[8,9]$. Finally, generalizability of HIT impact studies is hampered by methodological concerns $[10,11]$. The majority of studies used retrospective, self reported data, focused mainly on HIT system users, usually physicians, and evaluated a single type of HIT system, such as provider order entry. Thus, best implementation methods remain largely unknown.

HIT impact studies identified unanticipated social effects, such as reallocated work [12], interrupted work processes $[11,13]$, altered information exchange, communication patterns, and interpersonal relationships [11-15], and in some cases, patient harm [10,11]. Studies have also found that hospital staff member's perspectives about HIT processes for, and outcomes of, implementation varied by organizational identity [16], role [17], and work unit [9], causing variation in action. Care providers who perceived HIT as a threat, resisted using the HIT system [18-20]. Those who saw HIT as a benefit to patient care, on the other hand, used the system and advocated for system improvements [20,21]. Thus, care providers varied implementation experiences combined with differing expectations, objectives, and needs may contribute to the slow and uneven adoption of HIT in hospitals.

Project teams have not been well studied, even though they are responsible for implementing HIT. Project teamwork is a popular strategy that hospitals use to create change [22]. To develop solutions and anticipate consequences of change, hospitals populate teams with members with different experience, skill, and knowledge [23]. Diverse members bring new information to the team and they provide connections with others in the organization $[24,25]$. Thus, effective teamwork facilitates collaboration, coordinated effort, and task accomplishment [13]. Studies show that teams are usually better problem solvers than individuals perhaps because they represent the combined input of all members, or because team member interactions facilitate learning associated with shared expertise and social interaction [26-29].
During HIT implementation projects, hospitals need access to various knowledge and skills to uncover interdependencies and critical expectations, and to determine actions. Research on healthcare project teams noted that diverse membership and positive interpersonal interaction was associated with team innovativeness and positive organizational outcomes [25,28,30-32]. However, studies found that diverse perspectives also created conflict that was linked to poor team performance [28]. It appears necessary to carefully manage relationships between people to achieve benefits of diversity. Interpersonal interaction and diversity of team membership, therefore, are an important focuses of the proposed study; specifically, we focus on sensemaking processes of the team.

\section{Theoretical framework: sensemaking}

Sensemaking, a social process of searching for answers and meaning, drives the actions people take [33]. Sensemaking occurs through verbal discourse between hospital staff members. Whether planned or unplanned, change challenges people's ability to understand what is happening, to anticipate what will happen, and to know what steps to take $[5,33,34]$, suggesting that sensemaking processes may be more important than decisionmaking processes for successful change. Because HIT implementation in hospital settings does not occur in a linear fashion and includes unpredicted, unexpected outcomes, implementation team members cannot expect to make optimal decisions $[11,15,35]$. They are forced to make 'good enough' choices and adjust as new information becomes available and understanding of circumstances changes [13]. When compared to traditional linear, process-focused perspectives on HIT-related change, such as decision making and diffusion of innovation [36,37], sensemaking may help us to better manage project team actions because it is a process that accounts for new information as events unfold and for social interaction and construction of meaning [38-41].

Research on sensemaking in hospital studies suggests several things. Organizational role, such as nurse, physician, or manager, influences the sense that staff members make of events [42-44]. The sense that hospital staff members make influences their choices and actions [45-47]. Through discourse with other staff members, hospital staff members construct the meaning of information and events and shape and reshape their understanding as events unfold and new information becomes available [46-48]. Project teamwork provides a formal mechanism for enhancing sensemaking. Through dialog, team members share varying perspectives on team tasks, construct the meaning of events as the HIT is implemented, and take action in response to evolving meaning. Through sensemaking, team members define what 
is happening, jointly revise their understanding, learn, and problem solve, setting the course for HIT implementation $[42,44,49]$. This view of sensemaking and the review of literature on project teams, thus serves as the basis for our methodological choices. Refer to Additional file 1 for additional reference material used in developing this study.

\section{Methods}

\section{Design}

We propose a qualitative, longitudinal multiple case study through which we will examine the evolving sensemaking of three multidisciplinary HIT project teams using direct observation and organizational document review. We will follow the activities of these teams throughout the pre-implementation phase of the project. We defined this period as the time between team formation and the first time the HIT is used by hospital staff in the provision of care [50]. Through our choice of methods, we plan to address the following four weaknesses in prior research on hospital HIT implementation, project teams and sensemaking: retrospective data collection; reliance on self-reported perceptions of HIT implementation; focus on single participant identity; and focus on single work units.

Following Institutional Review Board approval, we will contact the Chief Nursing Officer and Chief Information Officer to obtain permission to conduct the study. As an incentive, a consultation summarizing findings of the study with recommendations for future project teams will be provided to the organization and to the case study participants. Following a protocol described by Utley-Smith et al. [51], the consultation will serve as a method of disseminating research findings directly to study participants in the form of a summary of research findings and some recommendations related to teamwork strategies for more effective sensemaking. Knowledge participants gain during the consultation may validate study participants' project experience, influence decisions to participate in future projects, and enhance participants' IT implementation skills [52]. Subjects in prior research have reported that they perceived a direct benefit from such consultations and recommendations [51].

\section{Setting}

This study will be conducted within a single, academic, tertiary care hospital in the southeastern United States. Consisting of 834 beds in 33 nursing units, the hospital has a highly complex, interdependent care environment where changes in care practices, such as HIT implementation, may result in unexpected consequences. The hospital decided to implement an HIT system, an electronic nursing documentation system, in its 33 nursing units.
Because of the anticipated impact of this system, the hospital is forming a multidisciplinary project team comprised of nine sub-teams. Each sub-team will be tasked with a different aspect of the HIT project and staffed with a cross-section of clinical disciplines and functional business team members. Using selection criteria described below, each sub-team selected for inclusion will represent a single case. We anticipate that project team members will have little history of working together; thus, the unique knowledge each member brings to the team's tasks may be largely unknown by other members of the team and team management processes will be necessary.

\section{Sample selection}

\section{Selecting case study teams}

Prior research suggests that team members' perspectives on HIT implementation may differ based upon their departmental affiliation, professional training, organizational role, and hierarchical level [4,41-43]. Further, a team's roles and responsibilities may shape the discourse, meaning, and actions taken during the project [41]. Thus, to capture how sensemaking is influenced by team member diversity, we will select sub-teams of the larger project implementation team for in-depth case study using two criteria: the sub-team has a broad scope of project responsibility within the larger project team and its members have different social identities. Three of nine project implementation sub-teams meet the criteria of broad responsibility and diverse membership and thus will be included in-depth case study: the executive team, the communication team, and the implementation team. The executive team $(\mathrm{n}=9)$ will include administrative and clinical executives and directors from multiple departments, and has a broad scope in that it will provide resources for the project and ensure alignment of project goals with organizational strategic goals. The communication team $(\mathrm{n}=11)$ will include administrative, clinical, and technical directors, managers, and staff representing many organizational levels, and has a broad scope in that it will produce all organizational communication about the project including minutes, articles, video, and web-based documents. The implementation team $(\mathrm{n}=31)$ will include directors, managers, and front-line staff from nursing units, pharmacy, information technology, and hospital education, also representing many organizational levels. This team has a broad scope in that it will collect information about care practices, identify unit level information and care needs, and recommend modifications to the system in support of those needs.

The six sub-teams that will not be selected for indepth case study include the steering committee, the neonatal development team, the psychiatric development 
team, the device selection team, the training team, and the informatics team. These teams will have narrower scopes of responsibility (e.g., selecting equipment), or their membership will be homogenous (e.g., all psychiatric nurses). To understand how the overall project is unfolding across the nine teams, however, we will collect published minutes from meetings held by the six teams not directly observed to include in analysis of documents. Further, during case study sub-team meetings, an update on the work of all nine teams will be summarized and presented. During the executive, communication, and implementation team meetings, we will capture this information in the field notes. Together, these documents and field notes will provide us with information about events and actions of other teams that we do not directly observe.

\section{Measurement \\ Sensemaking}

Sensemaking will be measured qualitatively using direct observations of the executive, communication, and implementation teams; and project document review. This approach will capture multiple perspectives and rich data on HIT implementation events $[13,39,41]$. We derived a set of sensemaking behaviors from a literature review $[5,33,42,53,54]$, which we evaluated in a preliminary study, and used to developed an observation guide (Additional file 2: Appendix A [55]) intended to capture sensemaking and subsequent actions. We anticipate that through discourse in team meetings, members will share their unique knowledge (e.g., care processes within a department), their perspective on the HIT implementation, and their interpretation of information and events [56] that will then direct their actions [45]. The observation guide will also facilitate documenting the actions the teams plan to take and their anticipated results as well as the teams' reflections on the actions taken. Questions on the observation guide included the following: What information do participants share and how do they share it (e.g., past experience, information from others, hypothetical scenarios)? What interpretations, labels, and conclusions do team members express? What new ideas, decisions or proposed actions will be taken and by whom? What form does the discussion take? And, how do team members interact with each other?

The document review guide (Additional file 2: Appen$\operatorname{dix} B$ ) is designed to capture written discourse where the project team formally records and/or shares information with external constituents about the team's goals and actions taken related to the HIT implementation. Data collection will include date obtained, description of the document, date of event or contact associated with the document, significance of the document, and a brief summary of the contents.

\section{Participant demographic data}

Team member demographic data (Additional file 2: Appendix C) will be obtained by self-report at the time when participants are introduced to the study. Data collected will include current job title, current unit of assignment, tenure in their profession, tenure in the organization, tenure on the unit of assignment, highest educational level, highest educational level in the profession, technology experience, gender, age, and ethnicity/ race. These data will be used to explore variations in sensemaking because studies indicate that these are individual characteristics that are likely to influence sensemaking $[40,43,45,48]$.

\section{Data collection procedures Direct observation}

We will directly observe team meetings and activities (e.g., training sessions) throughout the study. During observations, we will observe and manually record verbal communications between team members, using field notes and jottings [57]. These notes will be typed directly into a laptop versus being handwritten on paper and transcribed at a later time [57]. We will also document observations, such as seating arrangement, note passing, and eye rolling. We will audio record the meetings to support the field notes and listen to the tapes to verify that the field notes accurately capture communications; the recordings will not be transcribed verbatim. All data will be tagged with date and time to capture emerging trends. Meetings will generally occur once a month and last approximately 60 to 90 minutes. Direct observations occur during regularly scheduled meetings pose minimal burden to participants. Field notes, jottings, and audio recordings are tantamount to meeting minutes. Electronic field notes will be formatted and imported into AtlasTI.

\section{Documents}

Documents related to the project (e.g., articles) and project records (such as meeting minutes, presentations, policies and procedures, and flyers), will be maintained by the HIT project team in a Lotus notes database, published to the hospital intranet for review by hospital staff members, and published in organizational periodicals and newsletters. These documents are produced by the committee and reflect the way in which they wish to represent their work to external constituents. We will access documents electronically or in printed form from the intranet, and add them to the study database. Document date will be used to facilitate placement in and retrieval from the study database. Once formatted, documents will be imported into AtlasTI and summarized following the guide (Additional file 2: Appendix B). Documents will serve to corroborate and augment 
evidence from direct observation, or to contradict observational evidence $[42,57]$.

\section{Participant demographic data}

Participant consent for use of demographic data will be obtained after we provide a review of the nature of the study, participant's role, confidentiality, and the associated risk/benefits of participation. Participants will complete the survey tool described earlier (Additional file 2: Appendix C). As new team members are added, we will follow the demographic data collection procedure. The survey will take approximately 15 minutes to complete, posing minimal burden to participants. The demographic data will be entered into Microsoft Excel tables and accessed with SAS (v. 9.1) for analysis.

\section{Data analysis}

We will use qualitative analysis procedures recommended by Crabtree and Miller [57]. Our research team contains experts in health informatics; organizational cooperation and fairness; and organizational sensemaking and learning. As we develop hypotheses for each research aim, we will conduct research team discussions to uncover bias and propose alternate perspectives on emerging themes.

\section{Code development}

From the literature on sensemaking, we have developed an a priori set of codes (Additional file 2: Appendix D). Coding reduces the data so that the data remain manageable, facilitating data clustering and laying a foundation for further analysis [58]. Through iterative review and ongoing discussion between RK and RA, we will refine the definitions of each a priori code. When a segment of text does not fit an existing code, we will ask, 'What's going on here?' 'What triggered this participant action?' 'What follows this participant action?' 'How might sensemaking explain what is happening?' Through this opencoding technique, we will further develop our codes. We will develop decision rules and definitions to guide the categorization of data, and record these in the electronic codebook $[57,58]$. To minimize the loss of meaning that may occur when reducing data, we will record all data transition steps and retain original raw data, including meeting audio recordings, until the study is complete.

First, we will read the entire field note or document to get a sense of the whole and create an initial memo to capture our emerging impressions [58]. In a second reading, we will code units of text that described sensemaking events using our a priori codes. We will then create a second memo, summarizing initial ideas about the field note, documenting areas that need follow up [58]. Coded units will be sorted into categories and subcategories and analyzed for recurrent themes.
To address our research aims, we will use within-case and between-case analyses. To describe and compare sensemaking across multidisciplinary project teams, data will be analyzed for each case study sub-team so that we can gain a rich understanding of the sensemaking of each individual team [59]. In the cross-case analysis, for this aim, we will organize each team's sensemaking themes into three separate data matrices and compare across teams to establish similarities and differences among the teams. Because the three project teams' members differ in professional and organizational identity, it is likely that the teams will differ in terms of the sense they make of new information and project events. To describe how the sensemaking of temporary multidisciplinary project teams changes over time, we will analyze themes in temporal sequence. Since sensemaking is shaped by experience, it is likely that sensemaking of the project teams' members will shift following significant events. To describe how multidisciplinary project team's sensemaking influences the actions taken by the teams, we will organize the data matrices by the actions of each team in order to identify the antecedents and consequences of these actions. Finally, to identify which team member behaviors facilitate and or inhibit the sensemaking of a multidisciplinary project team, we will use open coding guided by the literature on project teams. Some examples of codes may include respect or openness to ideas. The coded data will be analyzed for themes that explain how team member behaviors either facilitate or inhibit team sensemaking.

\section{Assuring rigor}

We will use several established strategies to assure confirmability, dependability, and credibility $[57,58]$ in qualitative data collection and analysis. These are briefly described in Table 1. We will log all study material in a Microsoft Access database using a date/time/source stamp to facilitate access to these materials. This database will serve as the basis for an audit trail.

\section{Discussion}

This study appears to be the first to prospectively examine a multidisciplinary HIT implementation project team and its sub-teams. Hospitals often form project teams to provide a formal mechanism for sharing different perspectives on events, in this case, an HIT implementation, and developing solutions to implementation issues. The project team in this study represents a huge organizational investment in that more than 100 people will be involved in the project. Rather than using traditional, mechanistic models for studying HIT implementation in hospitals, we propose an innovative perspective-sensemaking-that reveals embedded social processes that shape large scale organization change. 
Table 1 Strategies for Ensuring Rigor

\begin{tabular}{ll}
\hline Criteria & Strategies to assure criteria are met \\
\hline Confirmability: unrecognized researcher biases & $\begin{array}{l}\text { RK and RA (and later the research team) serve as the check and balance for uncovering assumptions } \\
\text { and suggesting rival hypotheses. } \\
\text { Member checks will be used to confirm findings. }\end{array}$ \\
\hline Dependability: candidate performance & Guides will be used for all data collection. \\
\hline remains consistent over time & RK and RA will meet bi-weekly to review data collection and refine techniques. \\
& An electronic code book will be used to track all data transformations. \\
& RK and RA will read and each code at least 50\% of the field notes and compare coding. We will \\
& discuss and come to agreement about codes and interpretations. \\
\hline Credibility: results are plausible and authentic & Triangulation of data from multiple sources: direct observation (multiple healthcare disciplines and \\
& organizational hierarchical levels) and documents. \\
& Member checks will be used to confirm findings. \\
\hline
\end{tabular}

Effective sensemaking facilitates team members' understanding of what is happening, their learning, their problem solving, and, ultimately, the actions they take (or do not take) with regard to system implementation [40]. Prior research linked these activities to successful HIT implementation in non-hospital settings $[4,40,60,61]$. This study will: identify HIT implementation issues within the complex hospital environment and how team members deal with roadblocks and unexpected events; and describe the link between team member social interaction and implementation actions. These findings will lead to new methods of managing multidisciplinary project teams and implementing HIT in hospitals.

\section{Strengths and limitations}

We recognize several limitations inherent in our design choices. Our study will be conducted in a single, largescale academic hospital, thus generalizability of our findings to other types of healthcare organizations may be limited. We will neither interview individual project team members about their project team experience nor will we observe their interactions with people outside of the teams. However, because the sense the project team makes of ongoing implementation events is dependent upon verbal exchanges, we believe the choice to limit our observations to project team activities, such as meetings, will allow us to describe important discourse in sensemaking of HIT implementation. Finally, all project sub-teams will not be directly observed. However, we will note how our selected teams are keeping team members informed of other aspects of the overall project, and we will include documents from excluded subteams in our analysis.

Through our methodological choices, we aim to enrich the project team and hospital-based HIT implementation literature. Unlike many other studies, ours focuses on the people responsible for HIT implementation and will capture the interpretations and actions of a diverse group of project team members. Rather than relying on participant perceptions of events and potentially unreliable, retrospective data collection methods, the prospective case study design captures:

1. Key antecedents and consequences of ongoing, evolutionary, social process of implementing HIT.

2. Key internal and external factors that influence project teams including team composition, team member interaction, and interaction between project teams and the larger organization.

3. Key ways in which internal and external factors actually influence project team processes.

4. Key ways in which project team processes facilitate team task accomplishment.

The resulting in-depth, rich description of HIT implementation will facilitate determining how sensemaking differs among project teams, how sensemaking develops over time, what information and events teams respond to, what meaning is constructed, and what actions result from that meaning. Thus, this study will make a significant contribution to advancing our understanding of how project teams function within the complex hospital care environment and bring about organizational change.

\section{Additional material}

Additional file 1: Additional reference material used in developing the background and significance for the study.

Additional file 2: Appendix A (direct observation guide); Appendix B (document guide); Appendix C (participant demographic survey tool); and Appendix D (a priori code list)

\section{Acknowledgements}

This study and RK's salary was funded through three sources: a fellowship from Duke Health Technologies Solutions of Duke University Health System; Duke University School of Nursing and a NIH Roadmap/CTSA Summer 2007 grant, Califf PI, 1TL1RR024126-01. RM's salary was supported by the IC2 Institute at The University of Texas at Austin. We would like to thank Dr. Constance Johnson and Dr. E. Allan Lind for their contributions to study conception. 


\section{Author details}

'School of Nursing, Duke University, 307 Trent Drive, Durham, NC 27502, USA. ${ }^{2}$ Department of Management Science and Information Systems, McCombs School of Business, The University of Texas at Austin, 1 University Sta B6000, Austin TX 78712-0201, USA.

\section{Authors' contributions}

RK designed the study and drafted the manuscript. RA and RM guided study design and read and revised the manuscript. All authors read and approved the final manuscript.

\section{Competing interests}

The authors declare that they have no competing interests.

Received: 15 September 2010 Accepted: 29 November 2010 Published: 29 November 2010

\section{References}

1. Kirchhoff KT: State of the Science of Translational Research: From Demonstration Projects to Intervention Testing. Worldviews on Evidencebased Nursing 2004, 1:S6-S12.

2. Jha AK, DesRoches CM, Campbell EG, Donelan K, Rao SR, Ferris TG, Shields A, Rosenbaum S, Blumenthal D: Use of Electronic Health Records in U.S. Hospitals. N Engl J Med 2009, 360:1628-1638.

3. Jordan M, Lanham H, Crabtree B, Nutting P, Miller W, Stange K, McDaniel R: The role of conversation in health care interventions: Enabling sensemaking and learning. Implementation Science 2009, 4:1-15.

4. Stensaker I, Falkenberg J: Making sense of different responses to corporate change. Human Relations 2007, 60:137-177.

5. Weick KE, Sutcliffe KM, Obstfeld D: Organizing and the Process of Sensemaking. Organization Science 2005, 16:409.

6. Fretschner $\mathrm{R}$, Bleicher $\mathrm{W}$, Heininger $\mathrm{A}$, Unertl $\mathrm{K}$ : Patient data management systems in critical care. J Am Soc Nephrol 2001, 12:S83-S86

7. DeVore SD, Figlioli K: Lessons Premier Hospitals Learned About Implementing Electronic Health Records. Health Aff 2010, 29:664-667.

8. Lau F, Penn A, Wilson D, Noseworthy T, Vincent D, Doze S: The diffusion of an evidence-based disease guidance system for managing stroke. Int $J$ Med Inf 1998, 51:107-116

9. Paré G, Elam JJ: Introducing Information Technology in the Clinical Setting: Lessons Learned in a Trauma Center. Int J Technol Assess Health Care 1998, 14:331-343.

10. Kaushal R, Shojania KG, Bates DW: Effects of computerized physician order entry and clinical decision support systems on medication safety - A systematic review. Arch Intern Med 2003, 163:1409-1416.

11. Koppel R, Metlay JP, Cohen A, Abaluck B, Localio AR, Kimmel SE, Strom BL: Role of computerized physician order entry systems in facilitating medication errors. The Journal of the American Medical Association 2005, 293:1197-1203.

12. Ash JS, Berg M, Coiera E: Some unintended consequences of information technology in health care: the nature of patient care information system-related errors. J Am Med Inform Assoc 2004, 11:104-112.

13. Edmondson AC, Bohmer RM, Pisano GP: Disrupted routines: Team learning and new technology implementation in hospitals. Adm Sci $\mathrm{O}$ 2001, 46:685.

14. Campbell EM, Sittig DF, Ash JS, Guappone KP, Dykstra RH: Types of unintended consequences related to computerized provider order entry. J Am Med Inform Assoc 2006, 13:547-556.

15. Beuscart-Zephir MC, Pelayo S, Anceaux F, Meaux JJ, Degroisse M, Degoulet P: Impact of CPOE on doctor-nurse cooperation for the medication ordering and administration process. Int J Med Inf 2005, 74:629-641.

16. Ash JS, Sittig DF, Seshadri V, Dykstra RH, Carpenter JD, Stavri PZ: Adding insight: a qualitative cross-site study of physician order entry. Medinfo 2005, 11:1013-1017.

17. Doolin B: Power and resistance in the implementation of a medical management information system. Information Systems Journal 2004, 14:343-362.

18. Lapointe $L$, Rivard $S$ : A multilevel model of resistance to information technology implementation. Mis Quarterly 2005, 29:461-491.

19. Bar-Lev S, Harrison MI: Negotiating time scripts during implementation of an electronic medical record. Health Care Manage Rev 2006, 31:11-17.
20. Barber N, Cornford T, Klecun E: Qualitative evaluation of an electronic prescribing and administration system. Quality \& Safety in Health Care 2007, 16:271-278.

21. Aarts J, Berg M: Same systems, different outcomes - Comparing the implementation of computerized physician order entry in two Dutch hospitals. Methods Inf Med 2006, 45:53-61.

22. Devine DJ, Clayton LD, Philips JL, Dunford BB, Melner SB: Teams in organizations: Prevalence, characteristics, and effectiveness. Small Group Research 1999, 30:678-711.

23. Pinto MB, Pinto JK, Prescott JE: Antecedents and consequences of project team cross-functional cooperation. Management Science 1993, 39:1281.

24. Anderson RA, Issel LM, McDaniel RR: Nursing homes as complex adaptive systems: Relationship between management practice and resident outcomes. Nurs Res 2003, 52:12-21.

25. Ashmos DP, Huonker JW, McDaniel RR Jr: Participation as a complicating mechanism: the effect of clinical professional and middle manager participation on hospital performance. Health Care Manage Rev 1998, 23:7-20.

26. Cohen SG, Bailey DE: What makes teams work: Group effectiveness research from the shop floor to the executive suite. Journal of Management 1997, 23:239.

27. Edmondson AC: Psychological safety and learning behavior in work teams. Adm Sci Q 1999, 44:350

28. Nembhard IM, Edmondson AC: Making it safe: the effects of leader inclusiveness and professional status on psychological safety and improvement efforts in health care teams. Journal of Organizational Behavior 2006, 27:941.

29. Ford C, Sullivan DM: A time for everything: How the timing of novel contributions influences project team outcomes. Journal of Organizational Behavior 2004, 25:279-292.

30. Shortell SM, Marsteller JA, Lin M, Pearson ML, Wu SY, Mendel P, Cretin S, Rosen M: The role of perceived team effectiveness in improving chronic illness care. Med Care 2004, 42:1040-1048

31. Leykum L, Pugh J, Lawrence V, Parchman M, Noël P, Cornell J, McDaniel RR $\mathrm{Jr}$ : Organizational interventions employing principles of complexity science have improved outcomes for patients with Type II diabetes. Implementation Science 2007, 2:28-35.

32. Irvine Doran DM, Baker GR, Murray M, Bohnen J, Zahn C, Sidani S, Carryer J: Achieving clinical improvement: an interdisciplinary intervention. Health Care Manage Rev 2002, 27:42-56.

33. Weick KE: Sensemaking in Organizations London: Sage; 1995

34. Weick KE: Making Sense of the Organization Oxford: Blackwell; 2001.

35. Ash JS, Sittig DF, Campbell E, Guappone K, Dykstra RH: An unintended consequence of CPOE implementation: shifts in power, control, and autonomy. American Medical Informatics Association Annual Symposium Proceedings 2006, 11-15.

36. Van de Ven AH, Poole MS: Explaining development and change in organizations. Academy of Management The Academy of Management Review 1995, 20:510

37. Rogers E: Diffusion of Innovations. 5 edition. New York: Free Press; 2003.

38. Anderson RA, Ammarell N, Bailey D Jr, Colon-Emeric C, Corazzini KN, Lillie M, Piven ML, Utley-Smith Q, McDaniel RR Jr: Nurse assistant mental models, sensemaking, care actions, and consequences for nursing home residents. Qual Health Res 2005, 15:1006-1021.

39. Gioia DA, Thomas JB: Identity, image, and issue interpretation: Sensemaking during strategic change in academia. Adm Sci Q 1996, 41:370.

40. Balogun J, Johnson G: From Intended Strategies to Unintended Outcomes: The Impact of Change Recipient Sensemaking. Organization Studies 2005, 26:1573.

41. Maitlis S, Lawrence TB: Triggers and enablers of sensegiving in organizations. Acad Manage J 2007, 50:57.

42. Currie G, Brown AD: A narratological approach to understanding processes of organizing in a UK hospital. Human Relations 2003, 56:563.

43. Jensen TB, Aanestad M: How healthcare professionals 'make sense' of an electronic patient record adoption. Information Systems Management 2007, 24:29-42.

44. Apker J: Sensemaking of change in the managed care era: A case of hospital-based nurses. Journal of Organizational Change Management 2004, 17:211.

45. Blatt $R$, Christianson KM, Sutcliffe KM, Rosenthal MM: A sensemaking lens on reliability. Journal of Organizational Behavior 2006, 27:897. 
46. Torkelson DJ, Anderson RA, McDaniel RR: Interventions in response to chemically dependent nurses: effect of context and interpretation. Res Nurs Health 1996, 19:153-162.

47. Thomas JB, MCDaniel RR Jr, Anderson RA: Hospitals as Interpretation Systems. Health Serv Res 1991, 25:859-880.

48. Albolino S, Cook R, O'Connor M: Sensemaking, safety, and cooperative work in the intensive care unit. Cognition Technology Work 2007, 9:131-137.

49. Miller WL, McDaniel RR Jr, Crabtree BF, Stange KC: Practice jazz: Understanding variation in family practices using complexity science. The Journal of Family Practice 2001, 50:872-878.

50. Schwalbe K: Information Technology Project Management. 2 edition. Boston, MA: Course Technology; 2002.

51. Utley-Smith Q, Bailey D, Ammarell N, Corazzini K, Colon-Emeric CS, LekanRutledge D, Piven ML, Anderson RA: Exit interview-consultation for research validation and dissemination. West J Nurs Res 2006, 28:955-973.

52. Teekman B: Exploring reflective thinking in nursing practice. J Adv Nurs 2000, 31:1125-1135.

53. Gioia DA, Chittipeddi K: Sensemaking and sensegiving in strategic change initiation. Strategic Management Journal 1991, 12:433.

54. Weick KE, Roberts KH: Collective mind in organizations: Heedful interrelating on. Adm Sci Q 1993, 38:357.

55. Weick KE: Leadership as the legitimation of doubt. In The Future of Leadership: Today's Top Leadership Thinkers Speak to Tomorrow's Leaders. Edited by: Bennis WG, Spreitzer GM, Cummings TG. San Francisco, CA: Jossey-Bass; 2001:91-102.

56. Raes AML, Glunk U, Heijttjes MG, Roe RA: Top Management Team and Middle Managers: Making Sense of Leadership. Small Group Research 2007, 38:360-386.

57. Crabtree BF, Miller WL: Doing Qualitative Research. 2 edition. Thousand Oaks, CA: Sage; 1999.

58. Miles MB, Huberman AM: Qualitative Data Analysis: An Expanded Sourcebook. 2 edition. Newbury Park, CA: Sage; 1994.

59. Eisenhardt KM: Building Theories from Case Study Research. The Academy of Management Review 1989, 14:532-550.

60. Jordan ME, Lanham HJ, Crabtree BF, Nutting P, Miller WL, Stange KC, Mcdaniel RR: the role of conversation in health care interventions: Enabling sensemaking and learning. Implementation Science 2009, 4:1-15.

61. Vogelsmeier AA, Halbesleben JRB, Scott-Cawiezell JR: Technology implementation and workarounds in the nursing home. J Am Med Inform Assoc 2008, 15:114-119.

doi:10.1186/1748-5908-5-95

Cite this article as: Kitzmiller et al: Making sense of health information technology implementation: A qualitative study protocol.

Implementation Science 2010 5:95.

\section{Submit your next manuscript to BioMed Central and take full advantage of:}

- Convenient online submission

- Thorough peer review

- No space constraints or color figure charges

- Immediate publication on acceptance

- Inclusion in PubMed, CAS, Scopus and Google Scholar

- Research which is freely available for redistribution 